\title{
Primary pulmonary lymphoma in a patient with the acquired immune deficiency syndrome
}

\author{
DORIS POELZLEITNER, PETER HUEBSCH, SYLVIA MAYERHOFER, \\ ANDREAS CHOTT, CHRISTOPH ZIELINSKI
}

\author{
From the Radiological Division of the Second Medical Department, First Dermatological Department, and \\ Department of Pathology, University of Vienna, Austria
}

\begin{abstract}
A case of primary pulmonary lymphoma presenting as a nodular lesion on the chest radiograph in a patient with the acquired immune deficiency syndrome is described.
\end{abstract}

Patients with the acquired immune deficiency syndrome (AIDS) are predisposed to develop certain neoplasms, especially Kaposi's sarcoma and lymphoma. AIDS related lymphomas are predominantly high grade tumours of B cell origin. ${ }^{12}$ Though extranodal disease is common, ${ }^{13}$ primary pulmonary lymphoma-defined as lymphoma of the lung without extrathoracic manifestations within three months ${ }^{4}$ - has not been reported in a patient with AIDS.

\section{Case report}

A 45 year old homosexual man, known to be human immunodeficiency virus (HIV) positive since January 1987, developed Pneumocystis carinii pneumonia in August 1987. He completely recovered from this episode, and was treated with oral zidovudine $(3.5 \mathrm{mg} / \mathrm{kg}$ a day). Chest radiographs were normal until 1988, when a solitary, well defined nodular lesion was noted in the lower lobe of the left lung (fig 1). Neither mediastinal lymph node enlargement nor lymphadenopathy at any other site was present, and there had been no deterioration in the patient's clinical condition. Apart from anaemia associated with zidovudine there was no haematological abnormality. Computed tomography scans of brain, thorax, and abdomen were normal.

Because bronchoalveolar lavage and bronchoscopic biopsy gave inconclusive results, fine needle puncture of the lesion guided by computed tomography was carried out. ZielNielsen staining of the biopsy material showed acid fast bacilli, and epithelioid and giant cells were found on histological examination. Treatment with isoniazid, rifampicin, and ethambutol was started, but despite this the lesion grew to twice its previous size over the ensuing three months. A further computed tomography guided biopsy was performed in March 1988. The specimen obtained consisted

Address for reprint requests: Dr Doris Poelzleitner, Radiological Division of the Second Medical Department, Vienna Medical School, Garnisong 13, A-1090 Vienna, Austria. of necrotic material and giant cells; no acid fast bacilli could be found on this occasion.

To establish a definitive diagnosis the left lower lobe was resected in April 1988. The surgical specimen contained a round, well demarcated mass $7 \mathrm{~cm}$ in diameter, covered by pleura. On cross section it was grey, with extensive necrosis. Histological examination showed a high grade malignant lymphoma of large cell immunoblastic type; there was no evidence of tuberculosis, and no acid fast bacilli were present (fig 2). Three step immunoperoxidase staining of frozen sections indicated a mature B cell phenotype; $T$ cell and myelomonocytic differentiation antigens were not detected.

As repeat computed tomography of the brain, thorax, and abdomen again showed no lymphadenopathy or other manifestation of malignancy and the differential blood count was normal, a diagnosis of primary pulmonary lymphoma was made. No chemotherapy was given; there had been no relapse eight months later in November 1988.

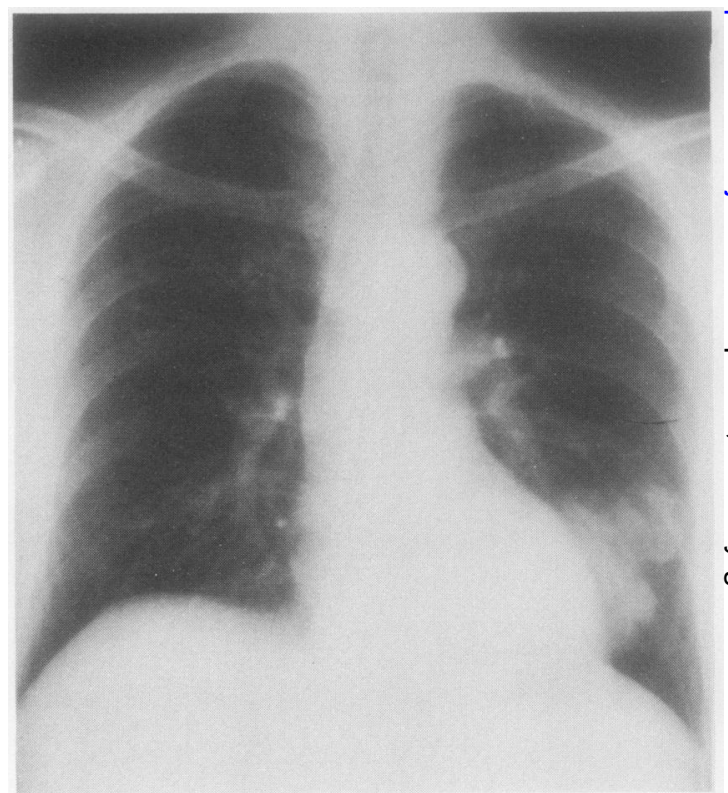

Fig 1 Well defined solitary nodular mass in the lower lobe of the left lung. 


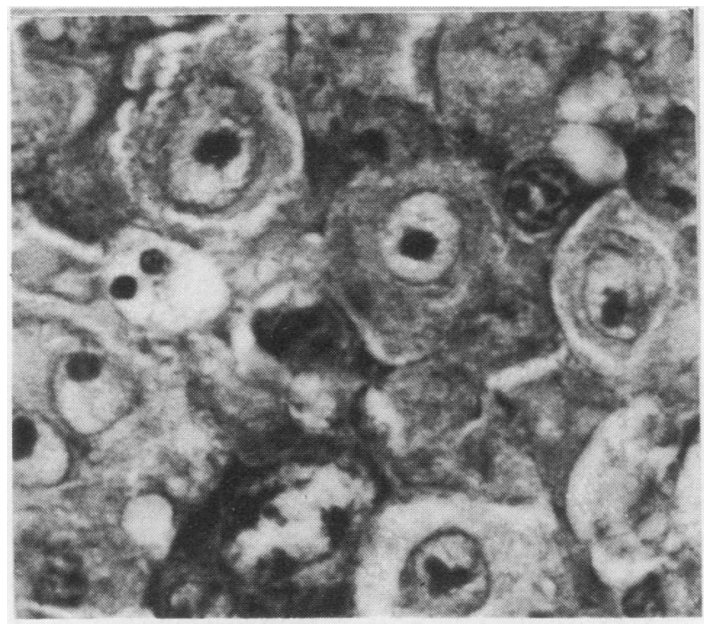

Fig 2 Section of the tumour showing large lymphoid cells with immunoblastic features.

\section{Discussion}

Immunosuppression, however caused, is associated with the development of malignant tumours, ${ }^{16}$ and in patients with AIDS neoplasms, including Kaposi's sarcoma and lymphoma, occur relatively frequently. ${ }^{7}$ Lymphomas are usually of the non-Hodgkin type, but Hodgkin's disease has been described. ${ }^{6}$ At the time of first manifestation these tumours are predominantly extranodal in origin, and are B cell neoplasms of high grade malignancy. Tumours of the central nervous system, gastrointestinal tract, liver, and bone marrow are frequent. Thoracic neoplasms are relatively rare, and primary pulmonary tumour with no extrathoracic distribution has not been reported.

Pulmonary lymphomas present radiologically as diffuse shadows or nodular lesions, with or without a pleural effusion. Mediastinal or hilar adenopathy may not be present. ${ }^{36}$ The diagnosis can be made with certainty only if there are no extrathoracic manifestations of disease either at presentation or up to three months later. If the hilum or mediastinum is affected most of the mass is usually within the lung. ${ }^{45}$

In our patient the exact nature of the pulmonary lesion was difficult to establish. The results of endoscopic biopsy and computed tomography guided needle puncture were in keeping with tuberculosis, and the correct diagnosis was made only after surgical resection. No acid fast bacilli were found in the tumour at the time of lobectomy. Their presence in the first biopsy material was probably due to a superinfection, which was cleared by antituberculous chemotherapy. Tuberculosis is a frequent complication of AIDS, and often atypical in its site and presentation. ${ }^{8}$

Owing to the high rate of complications associated with cytotoxic chemotherapy in patients with AIDS, ${ }^{9}$ we did not give any treatment. Nevertheless, our patient remains well eight months after the neoplasm first appeared.

\section{References}

1 Ziegler JL, Beckstead JH, Volberding PA, et al. Non-Hodgkin's lymphoma in 90 homosexual men. $N$ Engl J Med 1984;311: 565-70.

2 Egerter DA, Beckstead JH. Malignant lymphomas in the acquired immunodeficiency syndrome. Additional evidence for a B-cell origin. Arch Pathol Lab Med 1988;112:602-6.

3 Federle MP, Nyberg DA, Hulnick DH, Jeffrey RB. Malignant neoplasms: Kaposi's sarcoma, lymphoma, and other diseases with similar radiographic features. In: Federle M, Megibow A, Naidich DP, eds. Radiology of acquired immune deficiency syndrome. New York: Raven, 1988:107-29.

4 Gibbs AR, Seal RME. Primary lymphoproliferative conditions of the lung. Thorax 1978;33:140-52.

5 L'Hoste RJ, Filippa DA, Liebermann PH, Bretsky S. Primary pulmonary lymphomas-a clinicopathologic study of 36 cases. Cancer 1984;54:1397-406.

6 Kaplan MH, Susin M, Pahwa SG, et al. Neoplastic complications of HTLV-III infection: lymphomas and solid tumors. Am J Med 1987;82:389.

7 Baas AAF, van Herwaarden LA. Primary Non-Hodgkinlymphoma of the lung. Eur J Respir Dis 1986;68:218-23.

8 Goldmann KP. AIDS and tuberculosis. Br Med J 1987;295:511.

9 Gill PS, Levine AM, Krailo M, et al. Aids-related malignant lymphoma: result of prospective treatment trials. J Clin Oncol 1987;5:1322. 